\title{
ETS Domain-Containing Protein Elk-4
}

National Cancer Institute

\section{Source}

National Cancer Institute. ETS Domain-Containing Protein Elk-4. NCI Thesaurus. Code C97478.

ETS domain-containing protein Elk-4 (431 aa, $\sim 47 \mathrm{kDa}$ ) is encoded by the human ELK4 gene. This protein is involved in transcriptional regulation. 